Sports Science

\title{
Relative Age Effect on Brazilian male elite futsal athletes according to playing position and performance by goals scored on Brazil National Futsal Leagues
}

\begin{abstract}
Henrique de Oliveira Castro ${ }^{1,2}$ (D), Samuel da Silva Aguiar ${ }^{2,3}$ (D), Filipe Manuel Clemente ${ }^{4,5}$ (D), Ricardo Franco Lima ${ }^{4}$ (D), Gustavo De Conti Teixeira Costa ${ }^{6}$ (D), Lucas Savassi Figueiredo ${ }^{7}$ (D), Vivian de Oliveira ${ }^{8,9,10}$ (D), Sérgio Adriano Gomes ${ }^{11,12}$

${ }^{1}$ Universidade Federal de Mato Grosso, Cuiabá, MT, Brazil; ${ }^{2}$ Universidade Federal de Mato Grosso, Programa de Pós-Graduação em Educação Física, Cuiabá, MT, Brazil; ${ }^{3}$ Centro Universitário UDF, Brasilia, DF, Brazil; ${ }^{4}$ Instituto Politécnico de Viana do Castelo, Escola Superior de Desporto e Lazer, Viana do Castelo, Portugal; ${ }^{5}$ Instituto de Telecomunicações, Department of Covilhã, Covilhã, Portugal; ${ }^{6}$ Universidade Federal de Goiás, Goiânia, GO, Brazil; ${ }^{7}$ Centro de Instrução e Adaptação da Aeronáutica, Lagoa Santa, MG, Brazil; ${ }^{8}$ Centro Universitário IESB, Brasília, DF, Brazil; ${ }^{9}$ Centro Universitário UNIPLAN, Águas Claras, DF, Brazil; ${ }^{10}$ Universidade Estadual Paulista "Júlio de Mesquita Filho", Rio Claro, SP, Brazil; ${ }^{11}$ Universidade Católica de Brasília, Taguatinga, DF, Brazil; ${ }^{12}$ Centro Universitário UniCEUB, Brasilia, DF, Brazil.
\end{abstract}

Associate Editor: Ricardo Augusto Barbieri (D), Estácio UniSEB, Ribeirão Preto, SP, Brazil. Email: barbieri_ef@hotmail.com.

\begin{abstract}
Introduction: The relative age effect is prevalent in different elite team sports. However, little is known about this phenomenon in high-level adult male futsal players. Aim: The present study aimed to investigate the prevalence of relative age effect in Brazilian male elite futsal players, and its relationship with playing position and goals scored on Brazil National Futsal Leagues (BNFL) from 2016 to 2020. Methods: The distribution of birth dates, playing positions, and goals scored by male participants of the Brazil National Futsal Leagues were analyzed. Chi-squared tests were used to analyze the birth dates distribution based on quarters and semesters of the year, according to playing position (defender, winger, pivot, and goalkeeper) and scoring performance (high and low). Results: The overall analysis indicated that the relative age effect is prevalent on the pool of athletes analyzed. However, this effect was position-dependent, since relatively older athletes were overrepresented only in wingers and defenders playing positions. On the other hand, scoring performance was not associated with the relative age effect, since this effect was found in both performance levels. Conclusion: Relative age effects are prevalent in Brazilian male elite futsal athletes, especially for defenders and wingers. Considering the high level of competitiveness for spots in elite futsal teams, coaches and sports administrators must be educated about the prevalence of the relative age effect in this sporting context. This is necessary in order to reduce the inequalities generated by age categories based on arbitrary cut-off dates, which may reduce potential talent loss.
\end{abstract}

Keywords: RAE, futsal, birth-date, birth effect, talent selection.

\section{Introduction}

Relative Age Effect (RAE) reflects the asymmetrical distribution of athletes based on their birth date relative to an arbitrary cutoff ${ }^{1,2}$, and has been recently studied in several team sports, like cricket $^{3}$, handball ${ }^{4}$, beach handball ${ }^{5}$, basketball $^{6}$, ,ugby $^{7}$, soccer $^{8}$, volleyball ${ }^{9}$, and futsal ${ }^{1,10-12}$. Wattie, Schorer, and Baker ${ }^{13}$ propose that the existence of RAE and its extent in a given sports context can be inter- preted based on the interaction of individual, environmental, and task constraints. Individual constraints refer to an athlete's individual qualities, such as sex, height, body composition, maturational status, and so on. Environmental constraints relate to the sport's popularity, policies, and physical environment, among others. Task constraints concern the sports specificity, its competitive level, and the physical capabilities that are more important for success (i.e. strength, speed, and power). According to the 
specificities of a given sport context, it is expected that these constraints will interact to different degrees, contributing (or not) to the $\mathrm{RAE}^{13,14}$.

This effect can influence the recruitment of individuals in sports, as well as on how they develop their athletic abilities/skills ${ }^{2}$. Even though RAE has been extensively researched as a factor that can influence selection and talent identification in different team sports ${ }^{6,9}$, evidence on RAE prevalence over time is controversial and seemingly context-specific, such as the specificity of the sport's demands, competitive level, and popularity ${ }^{13}$, for example. On one hand, studies have shown that the advantage generated by the RAE during the phases of selection and identification is reversed over time, suggesting that RAE decreases and may even be reversed in the transition to elite sport ${ }^{15,16}$. On the other hand, other studies have reported that RAE prevalence remains up to senior elite sports in some contexts ${ }^{5,15}$.

Previous RAE investigations on team sports have sought to identify whether this effect would be associated with specific playing positions. Evidence on soccer ${ }^{17}$ and team handball ${ }^{4}$ indicate that RAE is more prevalent in specific playing positions in which physical capabilities are more determinant for success. Furthermore, some RAE investigations are trying to determine whether this effect is associated with competitive success. To illustrate, Arrieta et al. ${ }^{18}$ found that relatively older players scored more points and showed increased performance index ratings compared to relatively younger athletes in European Basketball Championships. However, the investigation of the association between RAE and the performance obtained during games in team sports is still limited.

Officially recognized by the Fédération Internationale de Football Association (FIFA), futsal is played by two teams composed of five players (four court players and one goalkeeper) on a $40 \times 20$ m indoor court with two $3 \times 2$ goals $^{19}$. The modality is described as a multiplesprint sport with an intermittent high-intensity activity ${ }^{20}$. Its popularity has improved in recent years and more than 12 million players are involved in the sport ${ }^{20}$. Despite futsal's popularity and media coverage on some of its major competitions, little research has been done on it, especially if compared to the sport it originated from, i.e. soccer $^{11}$. Futsal is a very widespread sport in Brazil. The Brazilian National Team participated in all editions of the World Championship (organized by International Indoor Football Federation - FIFUSA and FIFA) and won seven titles. The Brazilian National Team also participated in 22 editions of the America Cup (organized by FIFUSA and FIFA) and won 19 titles. Considering that the social context, the level of competition, the popularity, and the number of active participants may affect the presence of $\mathrm{RAE}^{21}$, new studies focused on RAE prevalence among different team sports are necessary in order to account for context specificities $^{22}$.
Previous studies have shown that many successful male team sport athletes concentrate their birth dates in the first months of the age-year ${ }^{18,21}$. Furthermore, evidence suggests that RAE remains up to adult-elite professional players in some sports ${ }^{12,15}$. In general, RAE in elite athletes is justified by the following explanations: (a) relatively older athletes are more developed regarding several motor skills and physical capacities compared to younger peers, and (b) relatively older athletes are more likely to be perceived as talented by coaches compared to younger athletes, which makes them more likely to be selected for better teams $\mathrm{s}^{2,23}$.

Studies that investigated RAE in elite male futsal athletes are scarce ${ }^{1}$. Recent studies have been carried out with players who participated in three FIFA Futsal World Cups $\left(2008,2012\right.$, and 2016) ${ }^{1}$, and with players who participated in the first division of the Spanish National League between 2006 and $2015^{11}$. Nevertheless, to the best of our knowledge, only one study ${ }^{12}$ investigated the occurrence of RAE in Brazilian elite futsal athletes in the last ten years. However, only birth quartiles were analyzed in this study. Therefore, no previous research has analyzed the RAE in Brazilian male elite futsal players according to playing positions and performance by goals scored in the Brazil National Futsal Leagues (BNFL).

Identifying the pervasiveness of RAE in a given sports context has important implications, due to its influence on talent identification, sports systems organization, practitioners, and athletes ${ }^{24}$. Thus, this study aimed to investigate the existence of RAE in male Brazilian elite futsal athletes that participated in the first division of BNFL 2021 according to playing position and performance by goals scored in the BNFLs from 2016 to 2020 . As demonstrated in a previous study with Brazilian elite futsal athletes ${ }^{12}$, we hypothesize that RAE will be found in athletes regardless of playing positions or goals scored, due to the high competitive level of the BNFL.

\section{Methods}

\section{Participants}

This is a retrospective and descriptive study with a cross-sectional design ${ }^{25}$. The sample of this study was composed of 411 male elite futsal athletes (mean age $=25.61 \pm 5.83$ years), equivalent to all athletes of the 23 teams that competed in the BNFL 2021 first division. The athletes were organized according to their playing position: defender $(\mathrm{n}=80)$, winger $(\mathrm{n}=180)$, pivot $(\mathrm{n}=75)$ and goalkeeper $(\mathrm{n}=76)$; and performance by goals scored: high $(n=63)$ and low $(n=70)$. Regarding the goals scored, it is noteworthy that some athletes did not participate in all editions of the Leagues, others participate for the first time this year, and others did not score any goals (like some goalkeepers). For organization and 
analysis of the athletes according to goals performance, we ranked their performances based on goals scored in BNFLs from 2016 to 2020 and separated athletes based on the median value $($ median $=1.0)$. Athletes that surpassed the median were considered as high-performance and the athletes that did not surpass the median value were considered as low-performance. No inclusion or exclusion criteria were adopted.

\section{Data collection and procedures}

Data were retrieved from the BNFL official website during May 2021. The information included players' full names, date of birth, playing positions, and goals scored in the BNFLs from 2016 to 2020. All the information was available on the BNFL official website.

For the purpose of this study, we defined the birth year as beginning on January 1st, as used by the other studies in sports ${ }^{26}$. The data were tabulated in a spreadsheet, and the variables analyzed included the quarters of the year the athletes were born, as used in previous studies in futsal ${ }^{1,11,12}$ : first quarter: Q1 (January-March), secondquarter: Q2 (April-June), third quarter: Q3 (July-September), and fourth quarter: Q4 (October-December). The information of performance by goals scored in BNFLs from 2016 to 2020 was also retrieved from the BNFL official website.

\section{Statistical analysis}

The chi-square test $\left(\chi^{2}\right)$ was performed to identify differences between birth date distributions in relation to each playing position and goal performance, as previously proposed $^{11}$ in research with RAE in Brazilian elite male soccer. Athletes were divided into four quarters $(\mathrm{Q} 1, \mathrm{Q} 2$, Q3, and Q4), and 25\% was assumed as the expected frequency for each quarter, as proposed by Cotê et al. ${ }^{27}$. In addition, the same analysis was carried out considering the birthdate distribution in each semester (1st Sem.: JanuaryJune and 2nd Sem.: July-December), in which we assumed $50 \%$ as the expected distribution for each semester.

Whenever chi-squared tests were significant, the corrected residuals ( $z$-value) were calculated according to Beasley and Schumacher ${ }^{28}$. When the $\mathrm{z}$-value was less than -1.96 or greater than 1.96 the difference was considered significant. The statistical index to determine the size of the effect was Cramer's V (V) whenever the degrees of freedom $(d f)$ were above $1^{29}$; in the opposite case, the $\phi$ coefficient was used. For chi-squared analysis, the magnitude of the effect size was measured by calculating Cramer's V., according to $\mathrm{Cramer}^{30}$, if $d f=3$ (in all comparisons between birthdate quarters), $\mathrm{V}=0.06$ to 0.17 represented a small effect, $\mathrm{V}=0.18$ to 0.29 represented a medium effect and $\mathrm{V} \geq 0.30$ represented a large effect. Finally, Odds Ratio (ORs) for Q1 versus Q4 and 1st versus 2nd were calculated. Analyses were performed using the
Statistical Package for Social Sciences (SPSS), version 21.0 (Chicago, USA). The significance level was 0.05 .

\section{Results}

Table 1 shows the absolute distribution in quarters of the dates of birth of the elite male futsal athletes. Results show an overrepresentation of players born in the first quarters of the year $(\mathrm{Q} 1=32.12 \%$; $\mathrm{Q} 2=28.71 \%$; $\mathrm{V}=0.13$ ), as well as a reduced frequency of players born closer to the end of the year $(\mathrm{Q} 3=21.17 \%$; $4=18.00 \%$; $\mathrm{V}=0.09)$, with significant differences $(\mathrm{p}<0.05)$ between Q1 and Q2 compared to Q3 and Q4. Likewise, the chisquare revealed that the distribution of the first semester was significantly higher $(p<0.05)$ compared to the second semester.

This study also examined the birthdates distribution in quarters according to players' positions (Table 2). Uneven distributions were found for wingers $(p<0.05)$ and defenders $(p<0.05)$, with significant differences $(\mathrm{p}<0.05)$ between Q3 and Q4 compared to Q1 for the defenders and Q3 and Q4 compared to Q2 for the wingers. Furthermore, a statistical difference $(\mathrm{p}<0.05)$ was found between Q1 and Q4 for the pivots. Regarding the winger position, the RAE effect size was medium $(\mathrm{V}=0.19)$, while a large effect was observed for defenders $(\mathrm{V}=0.28)$.

Table 3 shows the birthdates distribution in quarters according to goal performance (low and high). The chisquare test did not find statistically significant differences in birthdates distribution between players belonging to the high and low-level goal performances $(\mathrm{p}>0.05$; $\mathrm{V}=0.79$ ). However, uneven distributions were found for players belonging to the low $(\mathrm{p}<0.05)$ and high $(\mathrm{p}<0.05)$ goals performance, with significant differences

Table 1 - Quarter of birth distribution of male Brazilian elite futsal athletes.

\begin{tabular}{|c|c|c|}
\hline Quarter of date of birth & Athletes (n) & Percentage (\%) \\
\hline Q1 & 132 & 32.12 \\
\hline Q2 & 118 & 28.71 \\
\hline Q3 & $87^{\mathrm{a}, \mathrm{b}}$ & 21.17 \\
\hline Q4 & $74^{\mathrm{a}, \mathrm{b}}$ & 18.00 \\
\hline $1^{\mathrm{st}}$ & 250 & 60.83 \\
\hline $2^{\text {nd }}$ & $161^{\mathrm{e}}$ & 39.17 \\
\hline$\chi^{2}$ & \multicolumn{2}{|c|}{21.04} \\
\hline$d f$ & \multicolumn{2}{|c|}{3} \\
\hline $\mathrm{p}$-value & \multicolumn{2}{|c|}{$<0.0001$} \\
\hline OR (Q1:Q4) & \multicolumn{2}{|c|}{1.12} \\
\hline OR $\left(1^{\text {st }}: 2^{\text {nd }}\right)$ & \multicolumn{2}{|c|}{1.55} \\
\hline
\end{tabular}

Q1 - Q4 = birth quarter; $\chi^{2}=$ Chi-square value; OR $=$ odds ratio; $\mathrm{Q} 1$ : $\mathrm{Q} 4=$ first quarter compared to fourth quarter; $1^{\text {st }}: 2^{\text {nd }}$ odds ratio from $1^{\text {st }}$ semester to $2^{\text {nd }}$ semester; a, b, c and d = pairwise Chi-square comparison different from Q1, Q2, Q3 and Q4, respectively (adjusted for multiple comparison); $\mathrm{e}=$ different from $1^{\text {st }}$. 
Table 2 - Distribution of birthdates according to playing position.

\begin{tabular}{|c|c|c|c|c|c|c|c|c|c|c|c|c|c|c|c|c|c|c|}
\hline \multirow[b]{2}{*}{ Variable } & \multicolumn{3}{|c|}{ Q1 } & \multicolumn{3}{|c|}{ Q2 } & \multicolumn{3}{|c|}{ Q3 } & \multicolumn{3}{|c|}{ Q4 } & \multirow[b]{2}{*}{$\chi^{2}$} & \multirow[b]{2}{*}{$d f$} & \multirow[b]{2}{*}{$\begin{array}{c}\text { p- } \\
\text { value }\end{array}$} & \multirow[b]{2}{*}{$\boldsymbol{V}$} & \multirow[b]{2}{*}{$\begin{array}{l}\text { OR (Q1: } \\
\text { Q4) }\end{array}$} & \multirow[b]{2}{*}{$\begin{array}{c}\text { OR } \\
\left(1^{\text {st }}: 2^{\text {nd }}\right)\end{array}$} \\
\hline & $\mathbf{n}$ & $\%$ & $\begin{array}{c}z- \\
\text { value }\end{array}$ & n & $\%$ & $\begin{array}{c}z- \\
\text { value }\end{array}$ & $\mathbf{n}$ & $\%$ & $\begin{array}{c}z- \\
\text { value }\end{array}$ & $\mathbf{n}$ & $\%$ & $\begin{array}{c}z- \\
\text { value }\end{array}$ & & & & & & \\
\hline $\begin{array}{l}\text { Playing posi- } \\
\text { tion }\end{array}$ & & & & & & & & & & & & & 3.08 & 9 & 0.961 & 0.50 & & \\
\hline Defender & 23 & 17.31 & -0.82 & 23 & 19.72 & 0.10 & $21^{\mathrm{b}}$ & 24.10 & 1.20 & $13^{\mathrm{b}}$ & 17.66 & -0.53 & 12.10 & 3 & 0.007 & 0.28 & 0.98 & 0.27 \\
\hline Winger & 59 & 44.37 & 0.22 & 53 & 45.32 & 0.42 & $35^{\mathrm{a}}$ & 40.22 & -0.82 & $33^{\mathrm{a}}$ & 44.59 & 0.21 & 10.09 & 3 & 0.018 & 0.19 & 0.99 & 0.23 \\
\hline Pivot & 24 & 18.02 & -0.18 & 21 & 17.91 & -0.11 & 14 & 16.17 & -0.61 & $16^{\mathrm{a}}$ & 21.60 & 0.86 & 6.22 & 3 & 0.101 & 0.11 & 0.83 & 0.31 \\
\hline Goalkeeper & 27 & 20.30 & 0.75 & 20 & 17.05 & -0.52 & 17 & 19.55 & 0.30 & 12 & 16.15 & -0.64 & 1.37 & 3 & 0.713 & 0.10 & 1.25 & 0.26 \\
\hline
\end{tabular}

Table 3 - Distribution of birthdates according to goal performance (goal per game).

\begin{tabular}{|c|c|c|c|c|c|c|c|c|c|c|c|c|c|c|c|c|c|c|}
\hline \multirow[b]{2}{*}{ Variable } & \multicolumn{3}{|c|}{ Q1 } & \multicolumn{3}{|c|}{ Q2 } & \multicolumn{3}{|c|}{ Q3 } & \multicolumn{3}{|c|}{ Q4 } & \multirow[b]{2}{*}{$\chi^{2}$} & \multirow[b]{2}{*}{$d f$} & \multirow[b]{2}{*}{$\begin{array}{c}\text { p- } \\
\text { value }\end{array}$} & \multirow[b]{2}{*}{$\boldsymbol{V}$} & \multirow[b]{2}{*}{$\begin{array}{c}\text { OR (Q1: } \\
\text { Q4) }\end{array}$} & \multirow[b]{2}{*}{$\begin{array}{c}\text { OR } \\
\left(1^{\text {st }}: 2^{\text {nd }}\right) \\
\end{array}$} \\
\hline & $\mathbf{n}$ & $\%$ & $\begin{array}{c}z_{-}^{-} \\
\text {value }\end{array}$ & $\mathbf{n}$ & $\%$ & $\begin{array}{c}z- \\
\text { value }\end{array}$ & $\mathbf{n}$ & $\%$ & $\begin{array}{c}z- \\
\text { value }\end{array}$ & $\mathbf{n}$ & $\%$ & $\begin{array}{c}z- \\
\text { value }\end{array}$ & & & & & & \\
\hline $\begin{array}{l}\text { Goal perfor- } \\
\text { mance }\end{array}$ & & & & & & & & & & & & & 2.46 & 3 & 0.482 & 0.79 & & \\
\hline Low & 70 & 52.59 & 1.32 & 50 & 42.71 & -1.46 & 42 & 48.34 & 0.00 & $\begin{array}{c}28^{\mathrm{a}} \\
\mathrm{b}, \mathrm{c}\end{array}$ & 49.12 & 0.11 & 9.49 & 3 & 0.023 & 0.21 & 1.87 & 0.18 \\
\hline High & 63 & 47.41 & -1.31 & 67 & 57.29 & 1.43 & $\begin{array}{c}45^{\mathrm{a}} \\
\mathrm{b}\end{array}$ & 51.66 & 0.01 & $29^{\mathrm{a}, \mathrm{b}}$ & 50.88 & -0.18 & 23.80 & 3 & 0.001 & 0.42 & 1.79 & 0.29 \\
\hline
\end{tabular}

Q1 - Q4 = birth quarter; $\chi^{2}=$ Chi-square value; $\mathrm{OR}=$ odds ratio; $\mathrm{Q} 1: \mathrm{Q} 4=$ first quarter compared to fourth quarter; $1^{\text {st }}: 2^{\text {nd }}$ odds ratio from $1^{\text {st }}$ semester to $2^{\text {nd }}$ semester.

$(\mathrm{p}<0.05)$ between Q4 compared with Q1, Q2, and Q3 for low and Q3 and Q4 compared to Q1 and Q2 for high goal performance. Regarding the low goal performance, the RAE was medium $(\mathrm{V}=0.21)$, while for the high goal performance a large effect was observed $(\mathrm{V}=0.42)$.

\section{Discussion}

To analyze the RAE phenomenon in high-level adult male futsal players, this study investigated the existence of RAE in male Brazilian elite futsal athletes that participated in the BNFL 2021 first division according to playing position and performance by goals scored in the BNFLs from 2016 to 2020 . Overall, results revealed a significant overrepresentation of players in the first and second quarters of the year in comparison to the third and fourth quarters. Playing positions analyses revealed different results since relatively older athletes were overrepresented in defenders and wingers, while even birthdate frequencies were found for pivots and goalkeepers. Analyses based on performance revealed no differences in players' birthdates between athletes with the low and high number of goals scored. Within each performance level, players born in the first quarters of the year were more frequent than players born in the last quarter of the year were. The RAE is a well-known research topic in sports sciences, namely considering that a potential difference of one year can influence the chances of player's selection over the youth categories $^{21,31}$. Although RAE can be constrained by concurrent factors such as maturation, it is possible to observe that players born closer to cut-off dates may have some advantage in sports where age categories are determined by the year of birth, due to the normal biological advances over the period $^{13}$. This may result in different opportunities provided to young players, which may affect the chances of achieving higher levels of competition over their sports career ${ }^{32}$.

In our study, significant differences between quarters of birthdate were found in the pool of players analyzed. Overall, athletes born in Q1 and Q2 were more represented than those born in Q3 and Q4 were. Such results are in line with previous studies conducted with the same population (Brazilian futsal players), in which athletes born in Q1 and Q2 were also more frequent ${ }^{33}$, although, in an opposite line, Carraco et al. ${ }^{1}$ suggested that being born in the early months of the year was not related to successful performances in futsal.

The prevalence of RAE on Brazilian elite futsal athletes is multifactorial; however, it is possible that selection based on morphological growth, and immediate performance in youth categories might represent some of the reasons for this effect ${ }^{32}$. Even though RAE is expected to play a determinant effect in the selection processes at the beginning of a sports career, evidence indicates that players born in the last semester of the year are less frequent even in senior categories ${ }^{22}$ and show shorter careers than 
relatively older athletes ${ }^{10}$. Conversely, a study that investigated the occurrence and effect size of a relative age effect in the first division of the Spanish National Futsal League revealed that the overrepresentation of players born close to the cut-off date was more evident in medium and high-level teams than in low-level teams ${ }^{11}$.

Although the pool of players analyzed in our study confirmed this tendency, we have advanced in the knowledge by analyzing birthdate distribution according to playing positions. Our results revealed significant differences for wingers and defenders. We found an overrepresentation of players born in Q1 compared to Q3 and Q4 for defenders and an overrepresentation of players born in Q1 and Q2 compared to Q3 and Q4 for wingers. In both cases, we confirmed the hypothesis that players born in the first semester of the year would be more frequent than players born in the second semester. On the other hand, even distributions were found for pivots and goalkeepers. We speculate that the specificity of the technical and tactical demands of these two playing positions minimize the influence of maturational advantages. Concerning the pivot players, their function is basically to receive the ball in the front line and to execute a pass to the winger or the defender ${ }^{34}$. Accordingly, Ohmuro et al. ${ }^{35}$ verified that adult Japanese futsal pivot players cover smaller distances with the ball than the wingers, which reinforces the notion that this playing position has specific demands that may rely less on physical capabilities than the other line positions in futsal.

Regarding goalkeepers, Spyrou et al. ${ }^{36}$ found that goalkeepers present higher body fat when compared to other playing positions. Agreeing with these results, Polito et al. ${ }^{37}$ concluded that teenage futsal goalkeepers showed a higher percentage of adiposity and lower metabolic demands (considering the distance covered, caloric expenditure, and average speed of movement) than players from the other positions. This is in line with finding from Soares and Tourinho Filho ${ }^{38}$, who indicated that the goalkeeper's actions during a match are mostly of low intensity. For this reason, the maturational advantage would not lead to benefits that would lead to the predilection of relatively older athletes, justifying the absence of the RAE for these athletes. Nonetheless, we emphasize that our data only comprised adults, so it is important to investigate the RAE in younger categories to confirm such speculations.

Motivated to determine if RAE plays a determinant role in players' performance, we tested such a hypothesis with no differences between players with low and highperformance levels (scoring). However, players born in the first semester were overrepresented in both performance levels. Therefore, RAE does not seem to influence elite futsal athletes' performance in terms of goals scored. Considering these results, and findings from another study that analyzed RAE prevalence in Brazilian elite futsal players, we propose that athletes should have similar opportunities to achieve high levels of competition, regardless of their month of birth, since this is not a determinant factor on performance ${ }^{12}$.

A limitation of the present study is the lack of data on goals scored in the Leagues of 17 athletes because these athletes competed in the BNFL for the first time in 2021. Considering the scarcity of studies that investigated RAE on futsal and the influence of multiple factors within each sports context, we suggest that future studies investigate the occurrence of RAE in professional futsal athletes according to gender, final classification in competitions, and selection for National Teams in different countries. In addition, athletes from different age categories and experience levels must be analyzed.

As practical implications, it is important to emphasize that coaches must be instructed regarding the consistent evidence that male players born in the first semester of the year are more likely to reach senior elite futsal teams in Brazil. This may be associated with how coaches conduct players' selection, as the strategies employed by coaches may be centered in immediate performance, which is constrained by transient aspects such as biological maturation or the physical status of players.

\section{Conclusion}

In summary, RAE is prevalent in the Brazilian male elite futsal context. This effect was not associated with scoring performance, but it was associated with specific playing positions, as reported in other teams sports. Relatively older athletes were overrepresented in wingers and defenders positions, while even distributions were found for goalkeepers and pivots. These findings reinforce that counter-RAE interventions are warranted in the Brazilian male elite futsal context and especially in the grassroots of this sports system. Coaches of youth categories need to be aware of the existence of RAE, as well as of ways to minimize this effect. After all, eventual benefits that arise from chronological advantages are transitory, and should not subsidize decision-making regarding athletes' long-term sports development.

\section{References}

1. Carraco DDS, Galatti LR, Massa M, Loturco I, Abad CCC. Centesimal age and relative age effect in elite futsal players. Int J Exerc Sci. 2020;13(6):329-41.

2. Lidor R, Maayan Z, Arnon M. Relative age effect in 14-to 18-year-old athletes and their initial approach to this effect Has anything changed over the past 10 years? Front Sports Act Living. 2021;3:622120. doi

3. Connor JD, Renshaw I, Doma K. Moderating factors influence the relative age effect in Australian cricket. PeerJ. 2019;7:36867. doi. eCollection 2019. doi

4. Figueiredo LS, Gantois P, Lima-Junior D, Fortes LS, Fonseca FS. The relationship between relative age effects and 
sex, age categories, and playing positions in Brazilian national handball teams. Motriz: J Phys Ed. 2020;26(4): e10200045. doi

5. Figueiredo LS, Ribeiro LC, Fialho JVAP, Silva DG, Gantois $\mathrm{P}$, Costa GCT, et al. Relative age effects and team performance among elite beach handball athletes. J Phys Educ Sport. 2020;20(6):3354-60. doi

6. Kálen A, Lundkvist E, Ivarsson A, Rey E, Pérez-Ferreirós A. The influence of initial selection age, relative age effect, and country long-term performance on the re-selection process in European basketball youth national teams. J Sports Sci. 2021;39(4):388-94. doi

7. Kelly AL, Till K, Jackson D, Barrel D, Burke K, Turnnidge J. Talent identification and relative age effects in English male Rugby Union Pathways: from entry to expertise. Front Sports Act Living. 2021;3:640607. doi.

8. Peña-González I, Javaloyes A, Sarabia JM, Moya-Ramón M. Relative age-related differences between different competitive levels and field positions in young soccer players. Res Sports Med. 2021;29(3):254-64. doi

9. Rubajczyk K, Rokita A. The relative age effect and talent identification factors in youth volleyball in Poland. Front Psychol. 2020;11:1445. doi

10. Ferreira SA, Nascimento MA, Cavazzotto TG, Weber VMR, Tartaruga MP, Queiroga MR. Relative age in female futsal athletes: implications on anthropometric profile and starter status. Rev Bras Med Esp. 2020;26(1):34-8. doi

11. Lago-Fuentes C, Rey E, Padrón-Cabo A, Prieto-Trancoso J, Garcia-Núñez J. The relative age effect in professional futsal players. J Hum Kinet. 2020;72:173-83. doi

12. Morales Júnior VR, Alves IVG, Galatti LR, Marques RFR. The relative age effect on Brazilian elite futsal: men and women scenarios. Motriz: J Phy Ed. 2017;23(3):e101704. doi

13. Wattie N, Schorer J, Baker J. The relative age effect in sport: a developmental systems model. Sports Med. 2015;45 (1):83-94. doi

14. Figueiredo LS, Silva DG, Oliveira BHG, Ferreira AG, Gantois P, Fonseca FS. Relative age effect in elite Brazilian track and field athletes are modulated by sex, age category, and event type. Motriz: J Phy Ed. 2021;27:e10210004621. doi

15. Joyner PW, Lewis JS, Dawood RS, Mallon WJ, Kirkendall DT, Garret Jr WE. Relative age effectffect: beyond the youth phenomenon. Am J Lifestyle Med. 2020;14(4):42936. doi

16. de la Rubia A, Bjorndal CT, Sánchez-Molina J, Yague JM, Calvo JL, Maroto-Izquierdo S. The relationship between the relative age effect and performance among athletes in World Handball Championships. PLoS ONE. 2020;15(3): e0230133. doi.

17. Figueiredo LS, Gomes LMS, Silva DG, Gantois P, Fialho JVAP, Fortes LS, et al. The relative age effect in Brazilian elite soccer according to age category, playing position, and competitive level. Hum Mov. (in press).

18. Arrieta H, Torres-Unda J, Gil SM, Irazusta J. Relative age effect and performance in the U16, U18 and U20 European basketball championships. J Sports Sci. 2015;34(16):15304. doi
19. FIFA - Fédération Internationale de Football Association. Futsal Laws of the Game 2020/21. FIFA, Switzerland; 2020. Available from: https://digitalhub.fifa.com $/ \mathrm{m} /$ 696d0a3986700a31/original/smrcs2kmmsngmf5tf1fi-pdf. pdf [Accessed 13th June 2021].

20. Beato M, Coratella G, Schena F. Brief review of the state of art in futsal. J Sports Med Phys Fitness. 2016;56(4):428-32.

21. Musch J, Grondin S. Unequal competition as an impediment to personal development: a review of the relative age effect in sport. Dev Rev. 2001;21(2):147-67. doi

22. Lupo C, Boccia G, Ungureanu AN, Frati R, Marocco R, Brustio PR. The beginning for senior career in team sport is affected by relative age effect. Front Psychol. 2019; 10:1465. doi

23. Johnston K, Wattie N, Schorer J, Baker J. Talent identification in sport: a systematic review. Sports Med. 2018;48 (1):97-109. doi.

24. Cobley S, Abbott S, Dogramaci S, Kable A, Salter J, Hintermann $\mathrm{M}$, et al. Transient relative age effects across annual age groups in national level Australian swimming. J Sci Med Sport. 2018;21:839-45. doi

25. Ranganathan P, Aggarwal R. Study designs: part 1 - an overview and classification. Perspect Clin Res. 2018;9 (4):184-6. doi

26. Cobley S, Baker J, Wattie N, McKenna J. Annual agegrouping and athlete development: a meta-analytical review of relative age effects in sport. Sport Med. 2009;39(3):23556. doi

27. Cotê J, Macdonald DJ, Baker J, Abernethy B. When "where" is more important than "when": birthplace and birthdate effects on the achievement of sporting expertise. J Sports Sci. 2006;24(10):1065-73. doi

28. Beasley TM, Schumacher RE. Multiple regression approach to analyzing contingency tables: post hoc and planned comparison procedures. J Exp Educ. 1995; 64(1):79-93. doi

29. Aron A, Aron EN, Coups EJ. Statistics for psychology. Upper Saddle River, Prentice-Hall; 2002.

30. Cramer H. Mathematical methods of statistics. Champaign, Princeton University Press; 1999.

31. Romann M, Rössler R, Javet M, Faude O. Relative age effects in Swiss talent development - a nationwide analysis of all sports. J Sports Sci. 2018;36(17):2025-31. doi

32. de la Rubia A, Lorenzo-Calvo J, Lorenzo A. Does the relative age effect influence short-term performance and sport career in team sports? A qualitative systematic review. Front Psychol. 2020;11:1947. doi

33. Penna EM, Moraes LCC de A. Efeito relativo da idade em atletas brasileiros de futsal de alto nível. Motriz: J Phy Ed. 2010;16(3):658-63. doi

34. Sarmento H, Bradley P, Anguera MT, Polido T, Resende R, Campaniço J. Quantifying the offensive sequences that result in goals in elite futsal matches. J Sports Sci. 2016;34 (7):621-9. doi

35. Ohmuro T, Iso Y, Tobita A, Hirose S, Ishizaki S, Sakaue K, et al. Physical match performance of Japanese top-level futsal players in different categories and playing positions. Biol Sport. 2020;37(4):359-65. doi

36. Spyrou K, Freitas TT, Marín-Cascales E, Alcaraz PE. Physical and physiological match-play demands and player 
characteristics in futsal: a systematic review. Front Psychol. 2020;6(11):569897. doi

37. Polito, LFT, Brandão MRF, Charro MA, Bocalin DS, Figueira Júnio AJ. Parâmetros de intensidade e sudorese de jogadores de futsal por posição de jogo. Rev Bras Med Esporte. 2015;2(5):355-9. doi

38. Soares BH, Tourinho Filho H. Análise da distância e intensidade dos deslocamentos numa partida de futsal, nas diferentes posições de jogo. Rev Bras Educ Fís Esporte. 2006;20 (2):93-101. doi

\section{Corresponding author}

Henrique de Oliveira Castro, Universidade Federal de Mato Grosso, Cuiabá, MT, Brazil.

E-mail: henriquecastro88@yahoo.com.br.

Manuscript received on July 12, 2021

Manuscript accepted on September 20, 2021

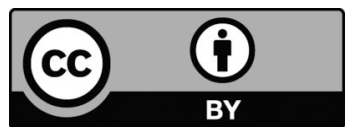

Motriz. The Journal of Physical Education. UNESP. Rio Claro, SP, Brazil - eISSN: 1980-6574 - under a license Creative Commons - Version 4.0 